\title{
Adenomatoid tumors of the male and female genital tract are defined by TRAF7 mutations that drive aberrant NF-kB pathway activation
}

Benjamin Goode ${ }^{1}$, Nancy M Joseph ${ }^{1,2}$, Meredith Stevers ${ }^{1}$, Jessica Van Ziffle ${ }^{1,2}$, Courtney Onodera ${ }^{2}$, Eric Talevich ${ }^{2}$, James P Grenert ${ }^{1,2}$, Iwei Yeh ${ }^{1,2}$, Boris C Bastian ${ }^{1,2}$, Joanna J Phillips ${ }^{1,3}$, Karuna Garg ${ }^{1}$, Joseph T Rabban ${ }^{1}$, Charles Zaloudek ${ }^{1}$ and David A Solomon ${ }^{1,2}$

${ }^{1}$ Department of Pathology, University of California, San Francisco, San Francisco, CA, USA; ${ }^{2}$ Clinical Cancer Genomics Laboratory, University of California, San Francisco, San Francisco, CA, USA and ${ }^{3}$ Department of Neurological Surgery, University of California, San Francisco, San Francisco, CA, USA

\begin{abstract}
Adenomatoid tumors are the most common neoplasm of the epididymis, and histologically similar adenomatoid tumors also commonly arise in the uterus and fallopian tube. To investigate the molecular pathogenesis of these tumors, we performed genomic profiling on a cohort of $\mathbf{3 1}$ adenomatoid tumors of the male and female genital tracts. We identified that all tumors harbored somatic missense mutations in the TRAF7 gene, which encodes an E3 ubiquitin ligase belonging to the family of tumor necrosis factor receptor-associated factors (TRAFs). These mutations all clustered into one of five recurrent hotspots within the WD40 repeat domains at the C-terminus of the protein. Functional studies in vitro revealed that expression of mutant but not wild-type TRAF7 led to increased phosphorylation of nuclear factor-kappa B (NF-kB) and increased expression of L1 cell adhesion molecule (L1CAM), a marker of NF-kB pathway activation. Immunohistochemistry demonstrated robust L1CAM expression in adenomatoid tumors that was absent in normal mesothelial cells, malignant peritoneal mesotheliomas and multilocular peritoneal inclusion cysts. Together, these studies demonstrate that adenomatoid tumors of the male and female genital tract are genetically defined by TRAF7 mutation that drives aberrant NF-kB pathway activation.
\end{abstract}

Modern Pathology (2018) 31, 660-673; doi:10.1038/modpathol.2017.153; published online 17 November 2017

Adenomatoid tumors are the most common neoplasm of the epididymis where they typically present as small, painless extra-testicular masses in young or middle age adults and are often diagnosed after orchiectomy. Histologically similar tumors also arise in the uterus and fallopian tube, which are also called adenomatoid tumors given their presumed relatedness. Adenomatoid tumors in women are similarly found in young or middle age adults where they are most often discovered incidentally during hysterectomy or salpingectomy for other clinical indications such as endometrial cancer, ovarian cancer or uterine leiomyomas. Apart from rare examples, adenomatoid tumors exhibit a benign

Correspondence: Dr DA Solomon, MD, PhD, Department of Pathology, University of California, San Francisco, 513 Parnassus Avenue, Box 0102, Health Sciences West 451, San Francisco, San Francisco, CA 94143, USA.

E-mail david.solomon@ucsf.edu

Received 2 August 2017; revised 15 September 2017; accepted 15 September 2017; published online 17 November 2017 clinical course without recurrence after resection and do not require additional therapy. Microscopically, they are poorly circumscribed neoplasms composed of a variable population of cuboidal to flattened cells with prominent cytoplasmic vacuolization arranged in cords with numerous cystically dilated spaces simulating vascular channels. The intervening stroma often contains abundant smooth muscle and elastic fibers and may have a prominent lymphocytic inflammatory infiltrate. Adenomatoid tumors of the male and female genital tract are presumed to be of mesothelial origin based on their morphological and ultrastructural features, as well as expression of markers typical of mesothelial cells and mesotheliomas including calretinin, WT1, D2-40 and cytokeratin. ${ }^{1-6}$

The molecular pathogenesis of these relatively common tumors of the male and female genital tract is unknown. Of note is a growing number of case reports documenting an association of adenomatoid tumors arising in patients who are immunosuppressed for treatment of autoimmune disease or 
following allograft organ transplantation, and rare examples of immunosuppressed patients with giant or multiple adenomatoid tumors have also been reported. ${ }^{7-11}$ This suggests a potential link between adenomatoid tumors and deregulated cytokine signaling pathways within mesothelial cells. Herein, we report the discovery of a defining genetic cause of adenomatoid tumors that may help to explain this association of adenomatoid tumors with immune dysregulation.

\section{Materials and methods}

\section{Study Population and Tumor Specimens}

This study was approved by the Institutional Review Board of the University of California, San Francisco. Thirty-one adenomatoid tumors from a cohort of 28 patients were retrieved from the pathology archives of our institution, spanning years 1994-2016. All tumor specimens had been fixed in 10\% neutral-buffered formalin and embedded in paraffin. Paraffin-embedded blocks of adjacent uninvolved testis, fallopian tube or uterus were also retrieved for each patient. Pathologic review of all tumor samples was performed to confirm the diagnosis by NMJ, KG, JTR, CZ and DAS.

\section{Targeted Next-Generation DNA Sequencing and Mutational Analysis}

Tumor tissue and uninvolved testis, fallopian tube or uterus was macrodissected from formalin-fixed, paraffin-embedded blocks for the 28 patients. Genomic DNA was extracted from the macrodissected tissue using the QIAamp DNA FFPE Tissue Kit (Qiagen) according to the manufacturer's protocol. Capture-based next-generation DNA sequencing was performed at the University of California, San Francisco Clinical Cancer Genomics Laboratory, using an assay that targets all coding exons of 479 cancer-related genes, select introns of 47 genes and TERT promoter with a total sequencing footprint of $2.8 \mathrm{Mb}$ (UCSF500 Cancer Panel; Supplementary Table 3). ${ }^{12}$ Sequencing libraries were prepared from genomic DNA, and target enrichment was performed by hybrid capture using a custom oligonucleotide library (Roche NimbleGen). Sequencing was performed on an Illumina HiSeq 2500. Duplicate sequencing reads were removed computationally to allow for accurate allele frequency determination and copy number calling. The analysis was based on the human reference sequence (NCBI build 37) using the following software packages: BWA: 0.7.13, Samtools: 1.1 (using htslib 1.1), Picard tools: 1.97 (1504), GATK: Appistry v2015.1.1-3.4.46-0ga8e1d99, CNVkit: 0.7.2, Pindel: 0.2.5b8, SATK: Appistry v2015.1.1-1-gea45d62, Annovar: v2016Feb01, Freebayes: 0.9.20 and Delly: 0.7.2..$^{13-20}$ Single-nucleotide variants and insertions/deletions were visualized and verified using Integrated
Genome Viewer. Genome-wide copy number analysis based on on-target and off-target reads was performed by CNVkit and Nexus Copy Number (Biodiscovery). ${ }^{16}$

\section{TRAF7 cDNA Expression Vector Construction and Site-Directed Mutagenesis}

A human wild-type TRAF7 cDNA (CCDS10461) with flanking 5' BamHI and 3' EcoRI restriction sites was synthesized by GenScript and cloned into the pCDF1-MCS2-EF1-Puro expression vector (System Biosciences). p.H521R, p.S561R and p.Y538S mutations were engineered into the pCDF1-TRAF7 construct by site-directed mutagenesis using the QuikChange II XL kit (Stratagene) as directed by the manufacturer. The coding sequence of all expression vectors was verified by Sanger sequencing. Primer sequences used for the mutagenesis reactions were as follows:

TRAF7 H521R Fwd: 5'-CTCACAGGCCTCAACCG CTGGGTGCGGGCCCTG-3',

TRAF7 H521R Rev: 5'-CAGGGCCCGCACCCAGC GGTTGAGGCCTGTGAG-3';

TRAF7 S561R Fwd: 5'-GACGTCTGGTGGCAGG GTCTACTCCATTGCTG-3',

TRAF7 S561R Rev: 5'-CAGCAATGGAGTAGACCC TGCCACCAGACGTC- $3^{\prime}$;

TRAF7 Y538S Fwd: 5'-CTGTACAGCGGCTCCT CCCAGACAATCAAGATC-3',

TRAF7 Y538S Rev: 5'-GATCTTGATTGTCTGG GAGGAGCCGCTGTACAG-3'.

\section{Cell Culture and Transfections}

293 T cells were obtained directly from ATCC and were maintained in Dulbecco's modified Eagle's medium supplemented with $10 \%$ fetal bovine serum at $37^{\circ} \mathrm{C}$ in $5 \% \mathrm{CO}_{2}$. Empty pCDF1 vector or pCDF1TRAF7 wild-type and mutant expression vectors were transfected into 293T cells using Fugene 6 (Roche) as described by the manufacturer.

\section{Western Blot}

Protein was extracted from 293T cells in RIPA buffer at $48 \mathrm{~h}$ after transfection, resolved by SDS-PAGE and immunoblotted following standard biochemical techniques. Primary antibodies used were phospho-NF-kB p65 Ser536 (Cell Signaling, clone 7F1), total NF-kB p65 (Cell Signaling, clone D14E12), L1CAM (Sigma, clone UJ127.11) and $\beta$-actin (Sigma, clone AC-15).

\section{Immunohistochemistry}

Immunohistochemistry was performed on whole formalin-fixed, paraffin-embedded tissue sections using anti-L1CAM antibodies (Sigma, clone UJ127.11) at a 1:1800 dilution following antigen 
Table 1 Clinicopathologic and genetic features of the 28 patients with adenomatoid tumors of the male and female genital tracts

\begin{tabular}{|c|c|c|c|c|c|c|c|c|c|c|c|}
\hline Patient \# & Age & Sex & Location & $\begin{array}{l}\text { Indication for biopsy/ } \\
\text { resection }\end{array}$ & $\begin{array}{l}\text { Hx of autoimmune } \\
\text { disease or } \\
\text { immunosuppression }\end{array}$ & $\begin{array}{l}\text { Size } \\
(\mathrm{cm})\end{array}$ & $\begin{array}{l}\text { TRAF7 } \\
\text { variant }^{\text {a }}\end{array}$ & $\begin{array}{l}\text { TRAF7 } \\
\text { variant }^{\text {a }}\end{array}$ & $\begin{array}{l}\text { Sequencing } \\
\text { reads over } \\
\text { TRAF7 } \\
\text { variant }\end{array}$ & $\begin{array}{l}\text { Allele } \\
\text { frequency } \\
\text { for TRAF7 } \\
\text { variant }\end{array}$ & $\begin{array}{l}\text { Additional somatic mutations } \\
\text { identified }\end{array}$ \\
\hline 1 & 43 & $\mathrm{M}$ & Epididymis & Testicular mass & None & 2 & p.Y538S & c. $1613 \mathrm{~A}>\mathrm{C}$ & 240 & $26 \%$ & - \\
\hline 2 & 31 & M & Epididymis & Testicular mass & None & 2 & p.S561R & c. $1683 \mathrm{C}>\mathrm{A}$ & 120 & $18 \%$ & - \\
\hline 3 & 33 & M & Epididymis & Testicular mass & N/A & 1 & p.Y538S & c. $1613 \mathrm{~A}>\mathrm{C}$ & 187 & $17 \%$ & - \\
\hline 4 & 42 & M & Epididymis & Testicular mass & N/A & 1 & p.Y538S & c. $1613 \mathrm{~A}>\mathrm{C}$ & 151 & $7 \%$ & - \\
\hline 5 & 47 & M & Epididymis & Testicular mass & $\begin{array}{l}\text { Immunosuppressed } \\
\text { status post kidney and } \\
\text { pancreas transplant }\end{array}$ & 2 & p.S561R & c. $1683 \mathrm{C}>\mathrm{G}$ & 700 & $4 \%$ & - \\
\hline 6 & 70 & M & Epididymis & Testicular mass & Ankylosing spondylitis & 1 & p.H521R & c. $1562 A>G$ & 415 & $5 \%$ & - \\
\hline 7 & 48 & M & Epididymis & Testicular mass & $\begin{array}{l}\text { Ulcerative colitis, on } \\
\text { immunosuppressive } \\
\text { therapy }\end{array}$ & 1 & p.Y577S & c. $1730 \mathrm{~A}>\mathrm{C}$ & 250 & $11 \%$ & - \\
\hline 8 & 43 & $\mathrm{~F}$ & $\begin{array}{l}\text { Fallopian } \\
\text { tube }\end{array}$ & $\begin{array}{l}\text { Menorrahagia, uterine } \\
\text { fibroids, and adnexal } \\
\text { mass found to be } \\
\text { hydrosalpinx with } \\
\text { associated ipsilateral } \\
\text { adenomatoid tumor }\end{array}$ & None & 1 & p.S561R & c. $1683 \mathrm{C}>\mathrm{G}$ & 453 & $15 \%$ & - \\
\hline 9 & 53 & $\mathrm{~F}$ & $\begin{array}{l}\text { Fallopian } \\
\text { tube }\end{array}$ & $\begin{array}{l}\text { Uterine endometrioid } \\
\text { adenocarcinoma }\end{array}$ & None & 1 & p.Y577S & c. $1730 \mathrm{~A}>\mathrm{C}$ & 1107 & $7 \%$ & - \\
\hline 10 & 35 & $\mathrm{~F}$ & $\begin{array}{l}\text { Fallopian } \\
\text { tube }\end{array}$ & Elective tubal ligation & None & 1 & p.S561R & c. $1683 \mathrm{C}>\mathrm{G}$ & 446 & $3 \%$ & - \\
\hline 11 & 72 & $\mathrm{~F}$ & $\begin{array}{l}\text { Fallopian } \\
\text { tube }\end{array}$ & Ovarian fibrothecoma & None & 1 & p.S561R & c. $1683 \mathrm{C}>\mathrm{G}$ & 518 & $1 \%$ & - \\
\hline 12 & 40 & $\mathrm{~F}$ & $\begin{array}{l}\text { Fallopian } \\
\text { tube }\end{array}$ & Elective tubal ligation & N/A & 1 & p.H521R & c. $1562 A>G$ & 160 & $8 \%$ & - \\
\hline 13 & 47 & $\mathrm{~F}$ & $\begin{array}{l}\text { Fallopian } \\
\text { tube }\end{array}$ & $\begin{array}{l}\text { Squamous cell carcinoma } \\
\text { of the cervix }\end{array}$ & Grave's disease & 1 & p.H521R & c. $1562 A>G$ & 524 & $12 \%$ & - \\
\hline \multirow[t]{4}{*}{14} & \multirow[t]{4}{*}{60} & \multirow[t]{4}{*}{$\mathrm{F}$} & \multirow[t]{4}{*}{$\begin{array}{l}\text { Fallopian } \\
\text { tube and } \\
\text { uterus }\end{array}$} & \multirow[t]{4}{*}{$\begin{array}{l}\text { Multiple adenomatoid } \\
\text { tumors, paratubal }(n=1) \\
\text { and myometrial }(n=3)\end{array}$} & \multirow[t]{4}{*}{$\begin{array}{l}\text { Immunosuppressed } \\
\text { status post heart and lung } \\
\text { transplant }\end{array}$} & \multirow[t]{4}{*}{$\begin{array}{l}1,6 \\
4,5\end{array}$} & p.H521R & c. $1562 \mathrm{~A}>\mathrm{G}$ & 253 & $21 \%$ & $\begin{array}{l}\text { FOXP1 p.A279T, MED12 p. } \\
\text { P1751L }\end{array}$ \\
\hline & & & & & & & p.S561R & c. $1683 \mathrm{C}>\mathrm{A}$ & 132 & $34 \%$ & $\begin{array}{l}\text { SETD2 p.S587fs, PTPRB p. } \\
\text { M1392V, FAT1 p. } \\
\text { N760delinsMVYAVSGGN }\end{array}$ \\
\hline & & & & & & & p.S561R & c. $1683 \mathrm{C}>\mathrm{G}$ & 417 & $27 \%$ & - \\
\hline & & & & & & & p.H521R & c. $1562 A>G$ & 258 & $24 \%$ & - \\
\hline 15 & 42 & $\mathrm{~F}$ & Uterus & $\begin{array}{l}\text { Giant uterine } \\
\text { adenomatoid tumor }\end{array}$ & $\begin{array}{l}\text { Systemic lupus } \\
\text { erythematosus, } \\
\text { immunosuppressed } \\
\text { status post kidney } \\
\text { transplant }\end{array}$ & 15 & p.Y577S & c. $1730 \mathrm{~A}>\mathrm{C}$ & 268 & $32 \%$ & LRP1B p.A2354D \\
\hline 16 & 43 & $\mathrm{~F}$ & Uterus & $\begin{array}{l}\text { Menorrahagia and uterine } \\
\text { fibroids }\end{array}$ & $\begin{array}{l}\text { Mixed connective tissue } \\
\text { disease, on } \\
\text { immunosuppressive } \\
\text { therapy }\end{array}$ & 1 & p.S561R & c. $1683 \mathrm{C}>\mathrm{G}$ & 184 & $15 \%$ & LRP1B p.L509V \\
\hline 17 & 48 & $\mathrm{~F}$ & Uterus & $\begin{array}{l}\text { Symptomatic uterine } \\
\text { fibroids }\end{array}$ & Grave's disease & 1 & p.H521R & c. $1562 \mathrm{~A}>\mathrm{G}$ & 348 & $9 \%$ & - \\
\hline
\end{tabular}




\begin{tabular}{|c|c|c|c|c|c|c|c|c|c|c|c|}
\hline Patient \# & Age & Sex & Location & $\begin{array}{l}\text { Indication for biopsy/ } \\
\text { resection }\end{array}$ & $\begin{array}{l}\text { Hx of autoimmune } \\
\text { disease or } \\
\text { immunosuppression }\end{array}$ & $\begin{array}{l}\text { Size } \\
(\mathrm{cm})\end{array}$ & $\begin{array}{c}\text { TRAF7 } \\
\text { variant }^{\text {a }}\end{array}$ & $\begin{array}{c}\text { TRAF7 } \\
\text { variant }^{\text {a }}\end{array}$ & $\begin{array}{c}\text { Sequencing } \\
\text { reads over } \\
\text { TRAF7 } \\
\text { variant }\end{array}$ & $\begin{array}{c}\text { Allele } \\
\text { frequency } \\
\text { for TRAF7 } \\
\text { variant }\end{array}$ & $\begin{array}{l}\text { Additional somatic mutations } \\
\text { identified }\end{array}$ \\
\hline 18 & 41 & $\mathrm{~F}$ & Uterus & $\begin{array}{l}\text { Menometrorrhagia and } \\
\text { extensive adenomyosis }\end{array}$ & $\begin{array}{l}\text { Immunosuppressed } \\
\text { status post kidney } \\
\text { transplant }\end{array}$ & 3 & p.H521R & c. $1562 A>G$ & 127 & $11 \%$ & - \\
\hline 19 & 46 & $\mathrm{~F}$ & Uterus & $\begin{array}{l}\text { Menometrorrhagia and } \\
\text { uterine fibroids }\end{array}$ & HIV infection & 1 & p.H521R & c. $1562 A>G$ & 322 & $3 \%$ & - \\
\hline 20 & 57 & $\mathrm{~F}$ & Uterus & $\begin{array}{l}\text { Uterine endometrioid } \\
\text { adenocarcinoma }\end{array}$ & None & 1 & p.S561R & c. $1683 \mathrm{C}>\mathrm{G}$ & 981 & $4 \%$ & SETD2 p.K280fs \\
\hline 21 & 57 & $\mathrm{~F}$ & Uterus & $\begin{array}{l}\text { Dysmenorrhea and } \\
\text { uterine adenomatoid } \\
\text { tumor }\end{array}$ & None & 5 & p.S561R & c. $1683 \mathrm{C}>\mathrm{A}$ & 200 & $12 \%$ & MED12 p.L36R \\
\hline 22 & 45 & $\mathrm{~F}$ & Uterus & $\begin{array}{l}\text { Uterine endometrioid } \\
\text { adenocarcinoma }\end{array}$ & None & 2 & p.S561R & c. $1683 \mathrm{C}>\mathrm{A}$ & 566 & $7 \%$ & - \\
\hline 23 & 55 & $\mathrm{~F}$ & Uterus & $\begin{array}{l}\text { Endometriosis and } \\
\text { ovarian endometriotic } \\
\text { cysts }\end{array}$ & None & 3 & p.H521R & c. $1562 A>G$ & 183 & $3 \%$ & RAD50 p.Q1263R \\
\hline 24 & 47 & $\mathrm{~F}$ & Uterus & $\begin{array}{l}\text { Menorrahagia and uterine } \\
\text { fibroids }\end{array}$ & None & 1 & p.H521R & c. $1562 A>G$ & 212 & $3 \%$ & - \\
\hline 25 & 42 & $\mathrm{~F}$ & Uterus & $\begin{array}{l}\text { Endometriosis and } \\
\text { ovarian endometriotic } \\
\text { cysts }\end{array}$ & None & 3 & p.H521R & c. $1562 \mathrm{~A}>\mathrm{G}$ & 380 & $2 \%$ & - \\
\hline 26 & 59 & $\mathrm{~F}$ & Uterus & $\begin{array}{l}\text { Cervical dysplasia and } \\
\text { uterine fibroids }\end{array}$ & None & 1 & p.S561R & c. $1683 \mathrm{C}>\mathrm{A}$ & 307 & $8 \%$ & $\begin{array}{l}\text { NUTM1 p.L949S, POLQ p. } \\
\text { H225L, SPTA1 p.E486Q }\end{array}$ \\
\hline 27 & 49 & $\mathrm{~F}$ & Uterus & $\begin{array}{l}\text { Dysmenorrhea and } \\
\text { uterine fibroids }\end{array}$ & None & 2 & p.S561R & c. $1683 \mathrm{C}>\mathrm{G}$ & 540 & $18 \%$ & SPEN p.P2516A \\
\hline 28 & 37 & $\mathrm{~F}$ & Uterus & $\begin{array}{l}\text { Menorrahagia and uterine } \\
\text { fibroids }\end{array}$ & None & 1 & p.L519P & c. $1556 \mathrm{~T}>\mathrm{C}$ & 465 & $3 \%$ & - \\
\hline
\end{tabular}

aAnnotated according to TRAF7 reference transcript NM_032271. 




C

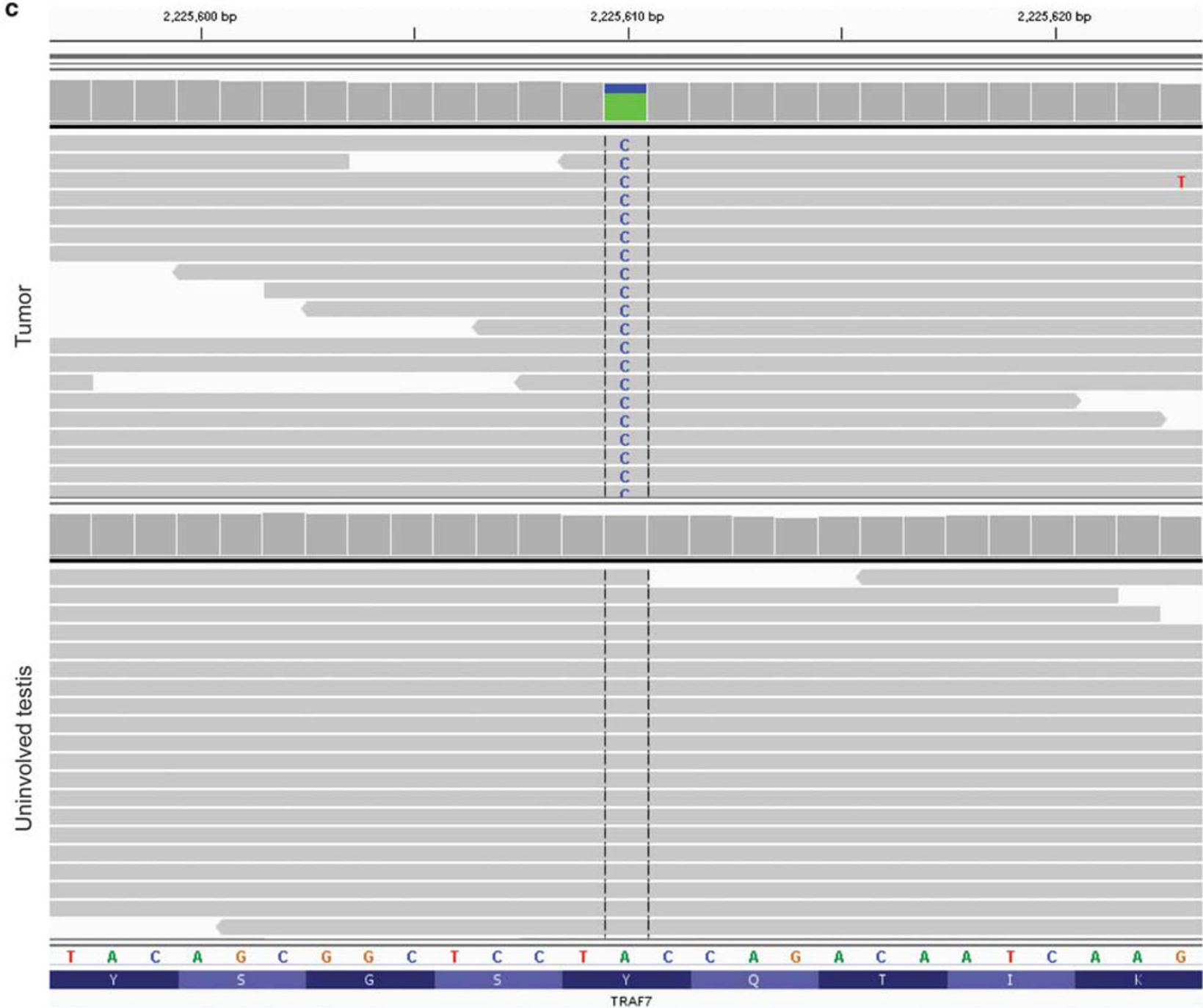

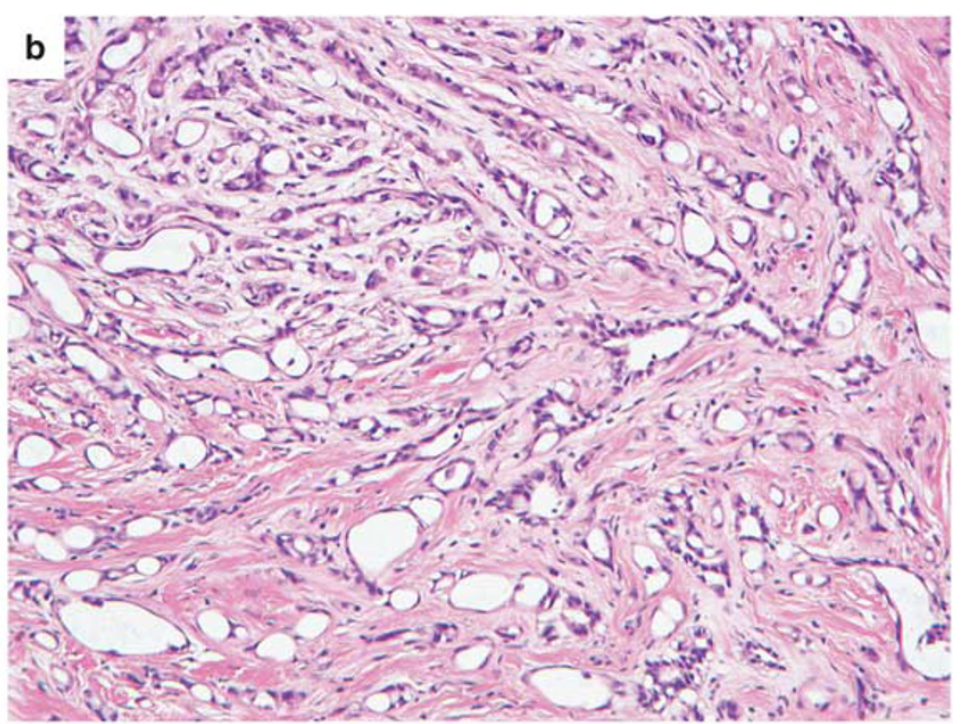

igure 1 Adenomatoid tumors of the epididymis are defined by somatic TRAF7 mutations. (a) Gross photo from patient \#1 showing a well-circumscribed nodule in the epididymis. (b) Hematoxylin and eosin (H\&E)-stained section of the tumor. (c) Next-generation sequencing reads from the tumor and adjacent uninvolved testis demonstrating a somatic TRAF7 p.Y538S missense mutation. 

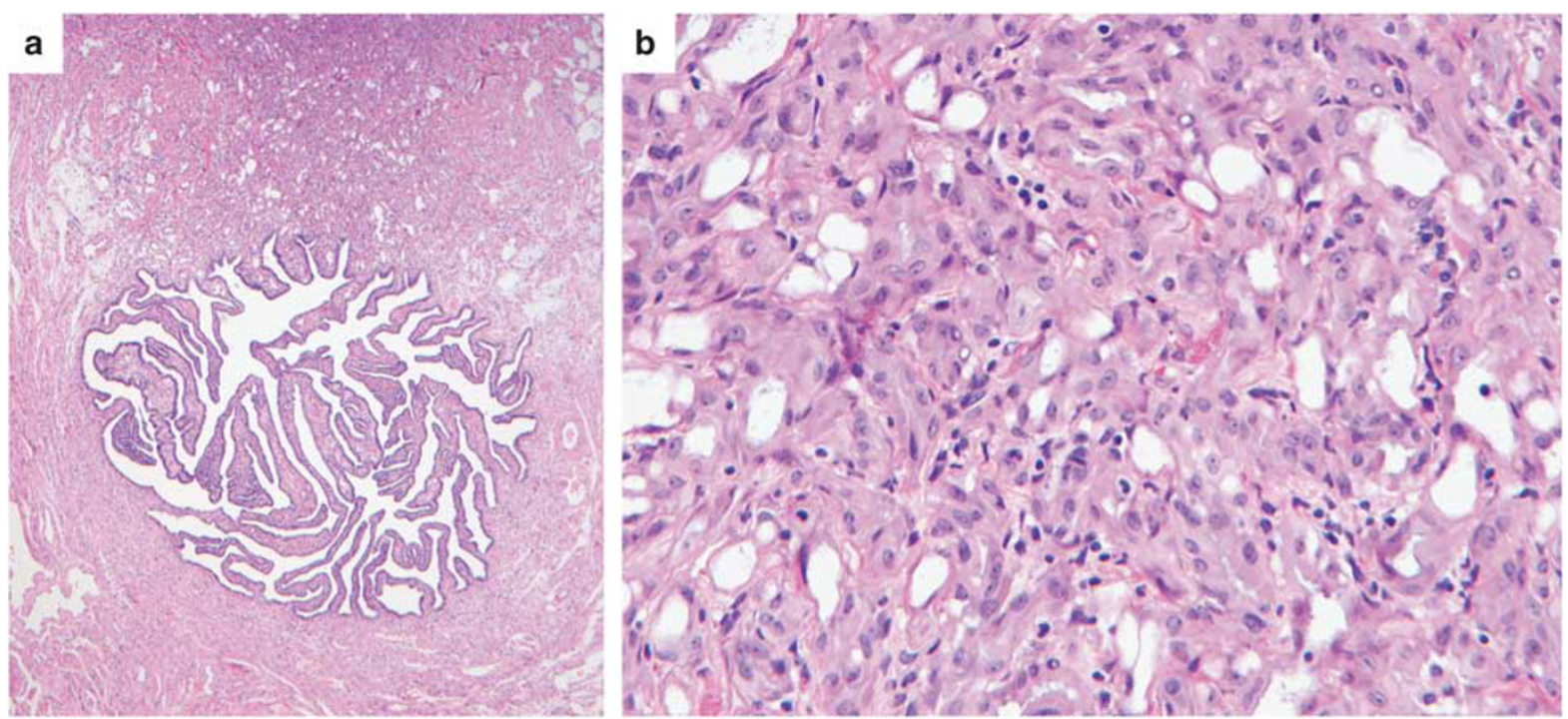

C

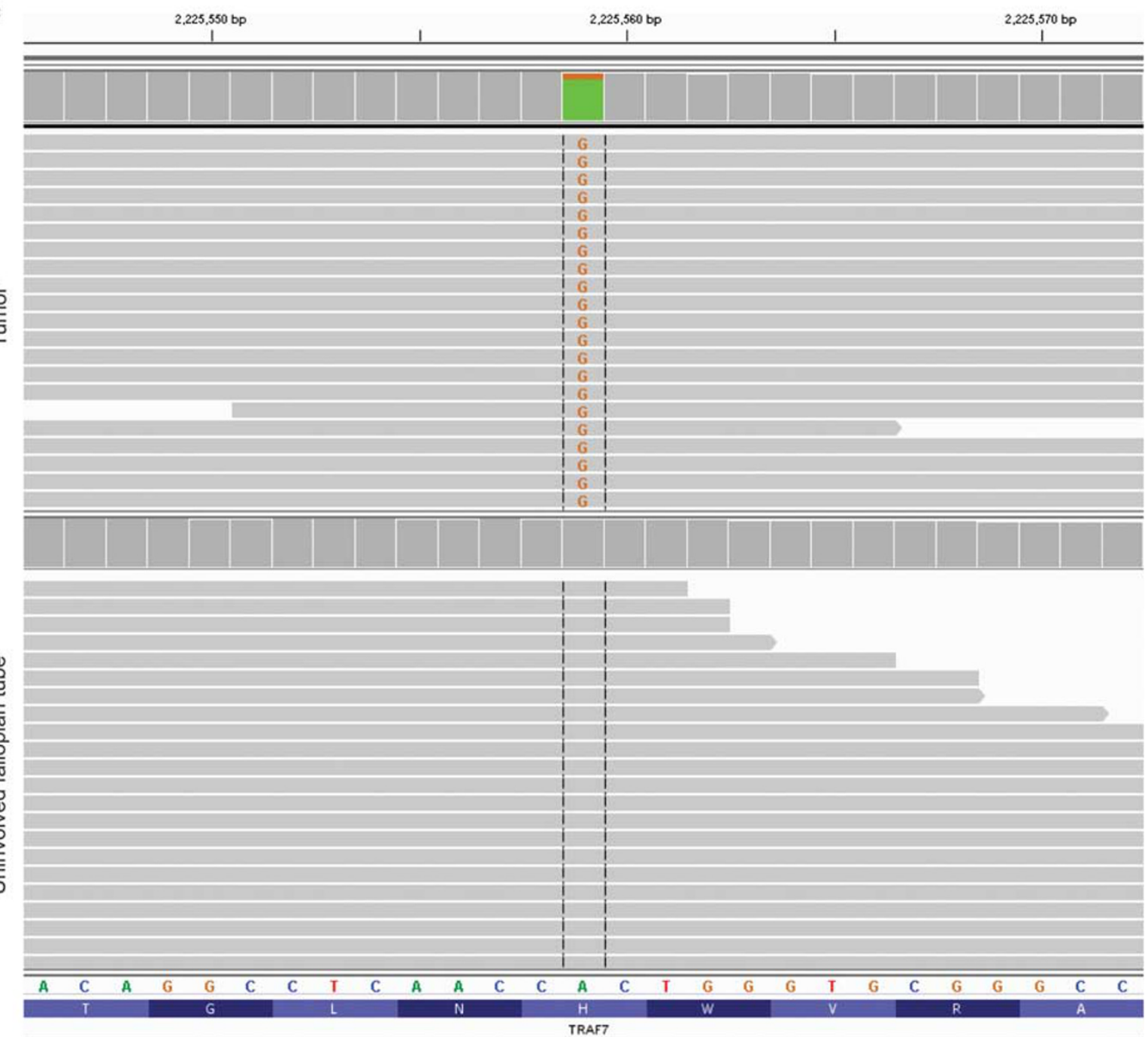

Figure 2 Adenomatoid tumors of the fallopian tube are defined by somatic TRAF7 mutations. (a) Hematoxylin and eosin-stained section from patient \#12 showing an ill-defined lesion within the paratubal soft tissue. (b) H\&E-stained section of the tumor. (c) Next-generation sequencing reads from the tumor and adjacent uninvolved fallopian tube epithelium demonstrating a somatic TRAF7 p.H521R missense mutation. 

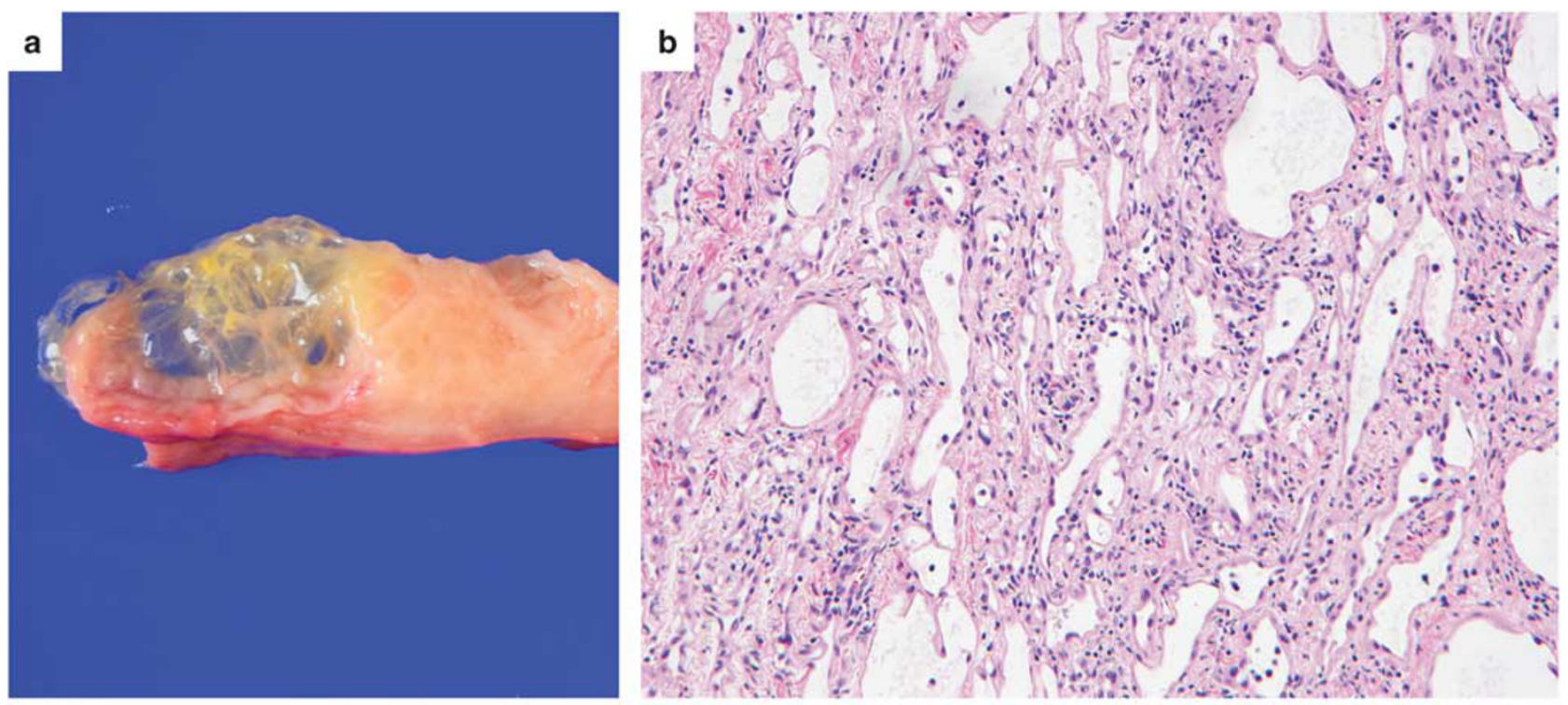

C

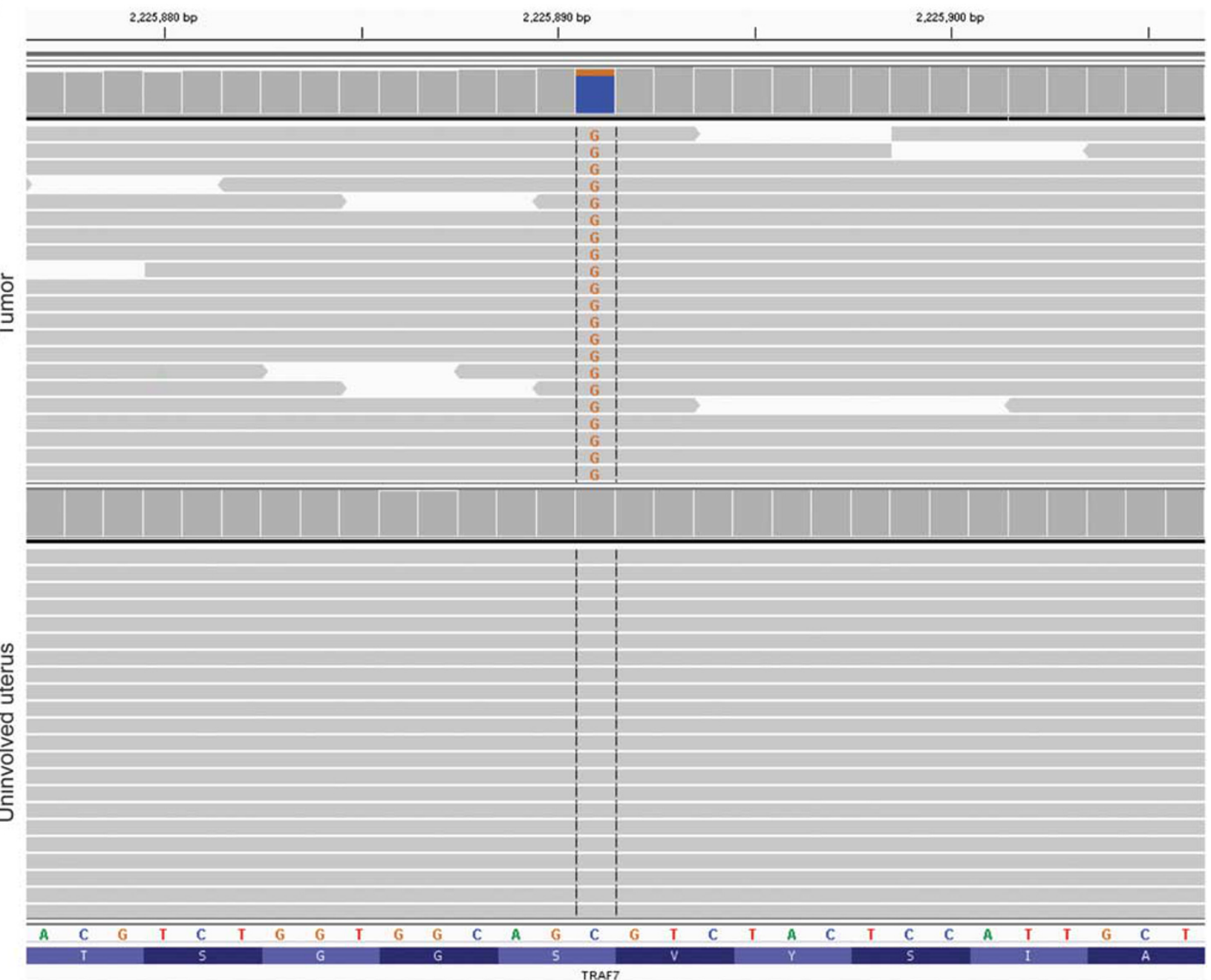

Figure 3 Adenomatoid tumors of the uterus are defined by somatic TRAF7 mutations. (a) Gross photo from patient \#21 showing an illdefined, yellow, multicystic lesion in the uterine body with extension into the broad ligament. (b) H\&E-stained section of the tumor. (c) Next-generation sequencing reads from the tumor and adjacent uninvolved uterus demonstrating a somatic TRAF7 p.S561R missense mutation. 
retrieval. All immunostaining was performed in a Ventana Benchmark automated stainer. Diaminobenzidine was used as the chromogen, followed by hematoxylin counterstain. This immunohistochemistry was performed on eight cases of adenomatoid tumor of the genital tract with confirmed somatic TRAF7 mutation, seven cases of normal mesothelial cells lining organs of the peritoneal cavity (four from ovarian surface and three from fallopian tube surface), seven cases of malignant peritoneal mesothelioma and six cases of multilocular peritoneal inclusion cyst. All specimens were from the pathology archives of our institution and had been fixed in $10 \%$ neutral-buffered formalin and embedded in paraffin. We have previously reported the clinical, histopathologic and molecular features for this cohort of malignant peritoneal mesotheliomas. ${ }^{12}$

\section{Results}

\section{Clinicopathologic Features of the Adenomatoid Tumor Patient Cohort}

In order to study the molecular pathogenesis of adenomatoid tumors of the male and female genital tracts, we assembled a cohort of matched tumor and normal tissue for 31 adenomatoid tumors from 28 patients for genomic analysis. The clinical features of this patient cohort are listed in Table 1 . The 7 male and 21 female patients ranged in age from 31 to 72 years (median 47 years). The seven male patients all had tumors located in the epididymis. The 21 female patients had tumors located in the fallopian tube $(n=7)$ or uterus $(n=17)$. The seven male patients all underwent total or partial orchiectomy for a painless testicular mass. The majority of the tumors in the 21 female patients were discovered incidentally upon hysterectomy or salpingectomy for other pathologic processes or elective tubal ligation. Ten of the 25 patients $(40 \%)$ with available clinical history had a history of immune dysregulation, which included autoimmune disease, HIV infection or immunosuppressive medical therapy following allograft organ transplantation. Tumors ranged in size from 1 to $15 \mathrm{~cm}$ (mean $2.3 \mathrm{~cm}$ ). One exceptional female (patient \#14) who was immunosuppressed following heart and lung transplant for congenital heart disease underwent hysterectomy and bilateral salpingooophorectomy at age 60 years and was found to have multiple distinct adenomatoid tumors, with

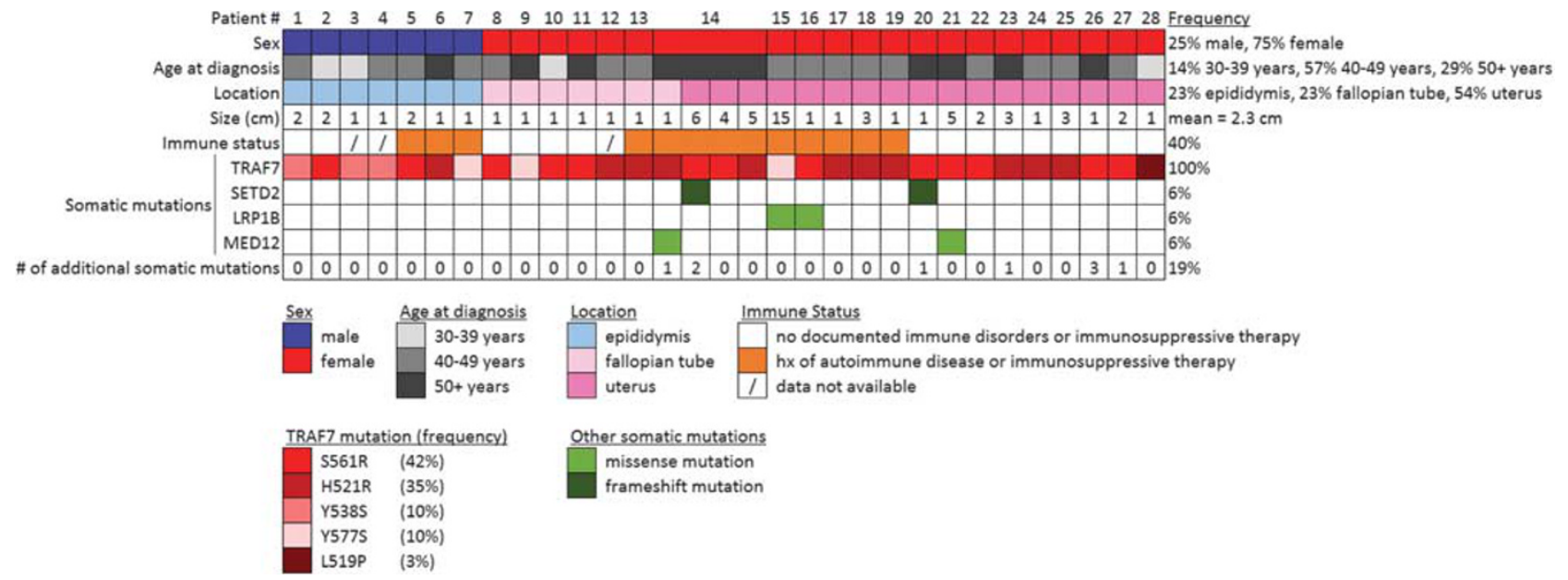

Figure 4 Genomic profiling results on 28 patients with adenomatoid tumors of the genital tract. Patient age, sex, immune status, tumor location, tumor size, TRAF7 mutation and other somatic mutations identified are shown.

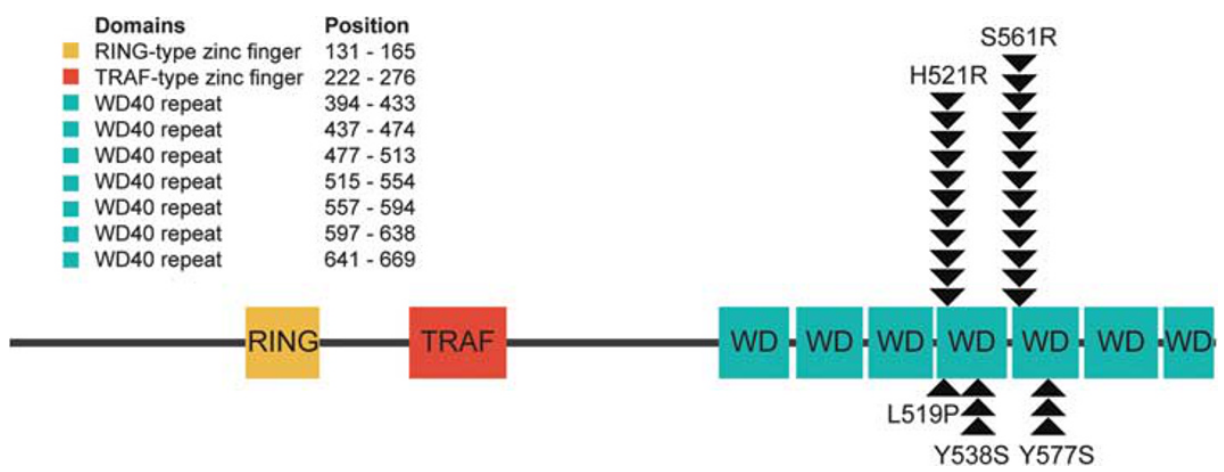

Figure 5 Diagram of human TRAF7 protein with the location of the somatic missense mutations identified in the 31 adenomatoid tumors of the genital tract. The mutations all cluster within one of five recurrent hotspots in the C-terminal WD40 repeats. 


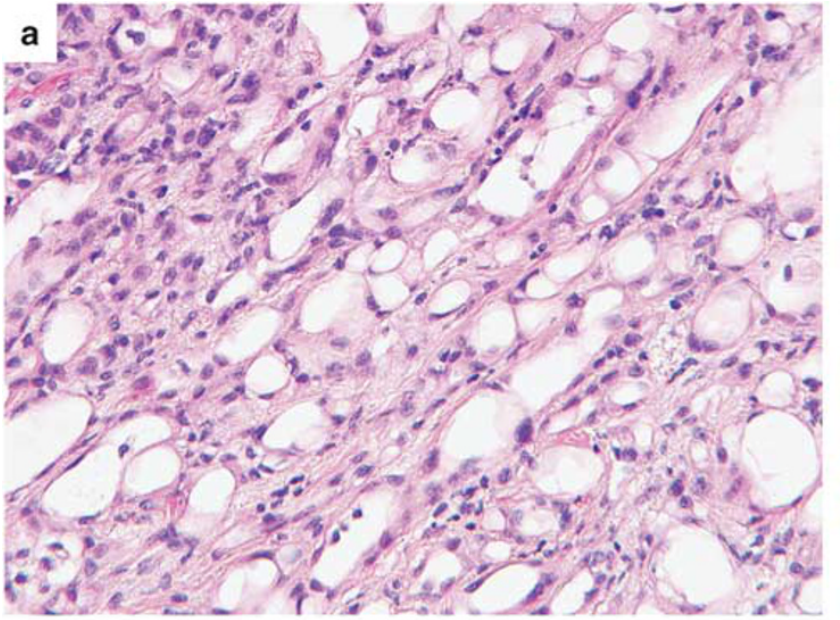

Fallopian tube, $1 \mathrm{~cm}$ nodule

TRAF7 p.H521R, c.1562A>G

additional FOXP1 and MED12 mutations

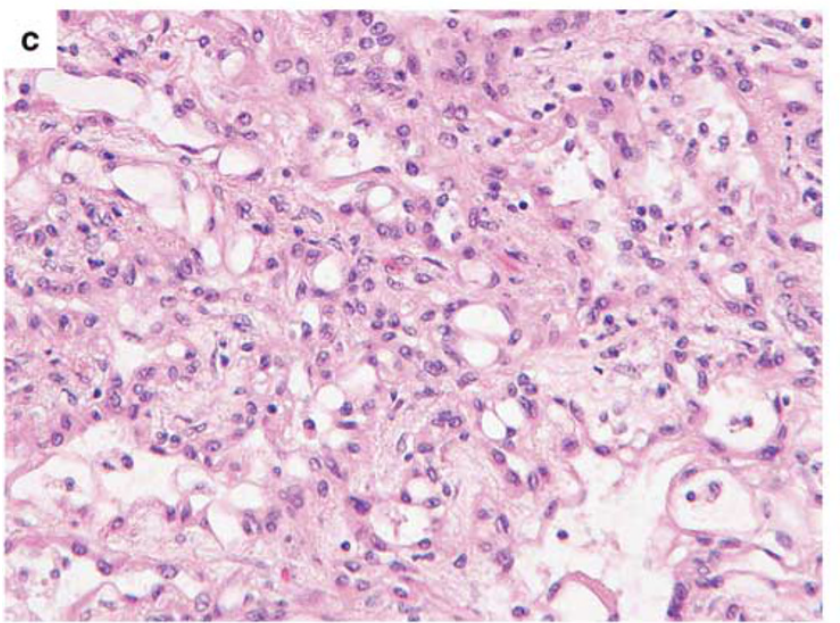

\section{Uterus, $4 \mathrm{~cm}$ mass}

TRAF7 p.S561R, c. $1683 \mathrm{C}>\mathrm{G}$

no additional mutations

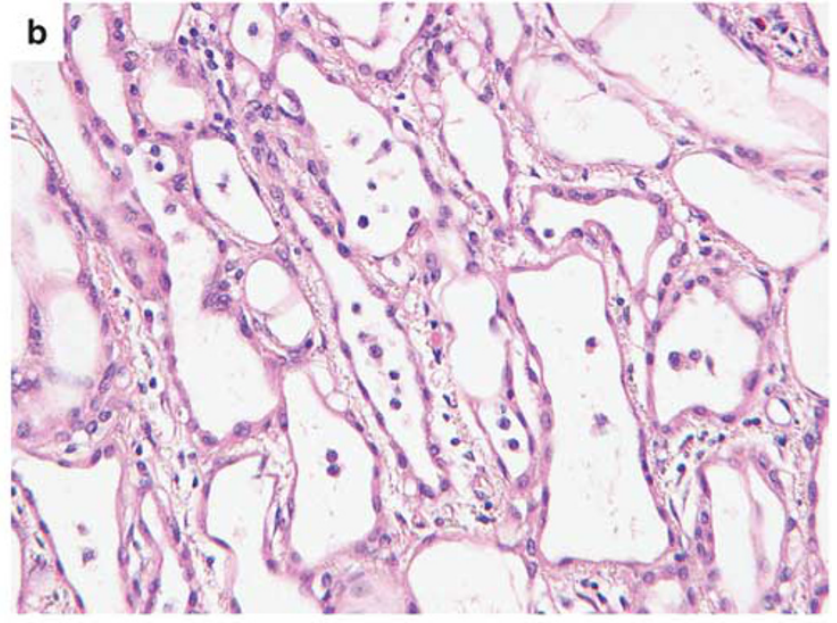

Uterus, $6 \mathrm{~cm}$ mass

TRAF7 p.S561R, c. 1683C>A

additional SETD2, PTPRB, and FAT1 mutations

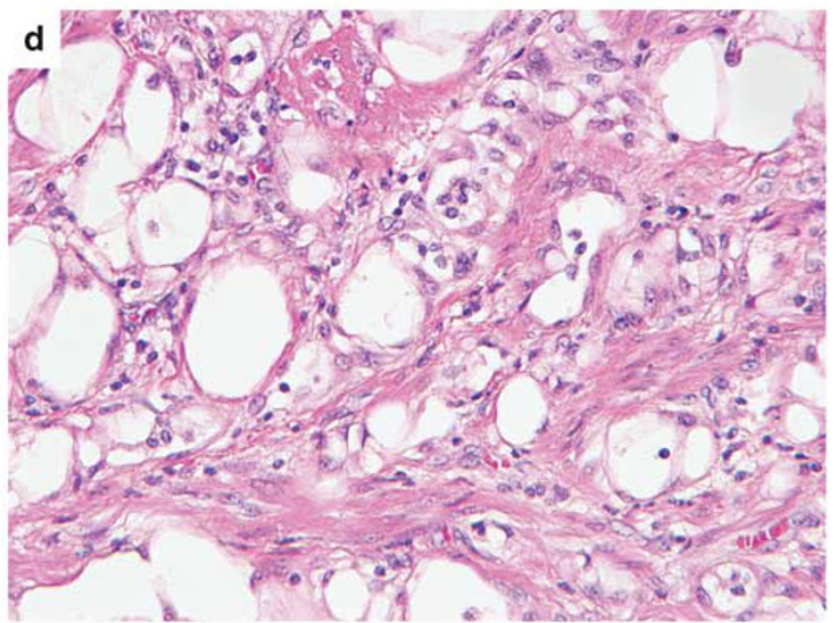

Uterus, $5 \mathrm{~cm}$ mass

TRAF7 p.H521R, c.1562A>G

no additional mutations

Figure 6 Multiple anatomically and genetically distinct adenomatoid tumors of the uterus and fallopian tube in an immunosuppressed patient post-transplant. A 60-year-old woman (patient \#14) who was on immunosuppressive medical therapy following heart and lung transplant for congenital heart disease underwent hysterectomy and bilateral salpingo-oophorectomy for presumed uterine fibroids. Pathology instead revealed multiple adenomatoid tumors, one located in the right fallopian tube (a) and three located in the uterus (b-d). Genomic analysis identified distinct TRAF7 mutations in each of the four tumors.

one in the fallopian tube and three in the uterus. Another exceptional female (patient \#15) who had systemic lupus erythematosus and was on immunosuppressive therapy following kidney transplant underwent hysterectomy for a giant adenomatoid tumor of the uterus $(15 \mathrm{~cm})$. After a median followup of approximately 12 months, no patients in this cohort experienced disease recurrence.

\section{Genomic Analysis of Adenomatoid Tumors of the Genital Tract}

Targeted next-generation sequencing was performed on genomic DNA isolated from the 31 tumors, as well as matched normal tissue, as described in the
Materials and methods section. This identified somatic missense mutations in the TRAF7 gene in all 31 tumors (Figures 1,2,3 and 4,Supplementary Table 1). Each tumor contained a single missense mutation in TRAF7, which encodes an E3 ubiquitin ligase and is a member of the family of tumor necrosis factor receptor-associated factors (TRAFs). The mutations all clustered into one of five hotspots located in the WD40 repeats at the C-terminus of the protein (Figure 5). The most common mutation was p.S561R occurring in 13/31 tumors (42\%) because of either a c.1683C $>\mathrm{G}(n=7)$ or c.1683C $>$ A $(n=6)$ substitution. The second most common mutation was p.H521R occurring in 11/31 tumors (35\%) because of c.1562 A $>\mathrm{G}$ substitution. Among the other seven tumors, three harbored p.Y538S 
mutation, three harbored p.Y577S and one harbored p.L519P. These TRAF7 missense mutations were verified to be somatic (ie, tumor specific) in all cases. The mutant allele frequency for the TRAF7 variants ranged from 1 to $34 \%$. Cases with the highest TRAF7 mutant allele frequencies had genomic DNA isolated from areas histologically visualized to contain a high tumor cell content. Cases with the lowest TRAF7 mutant allele frequency had genomic DNA that was isolated from tumors containing sparse tumor nuclei that were diffusely infiltrating the uterine myometrium. No chromosomal gains, losses or copy-neutral loss of heterozygosity involving the TRAF7 locus at chromosome 16p13.3 were identified in any of the tumors. Therefore, these data suggest that TRAF7 mutation is likely a clonal heterozygous alteration in adenomatoid tumors (ie, present in all tumor cells), indicating that it is probably an early or initiating event in tumorigenesis.

In addition to TRAF7 mutation, 9/31 tumors (29\%) contained somatic nonsynonymous mutations in at least one additional gene (Figure 4,Supplementary Table 2). Two of the 31 tumors $(6 \%)$ contained a frameshift mutation in SETD2, which encodes a histone methyltransferase with specificity for lysine36 of histone $\mathrm{H} 3$ and is recurrently mutated in renal cell carcinomas and pediatric gliomas. ${ }^{21,22}$ Two tumors contained missense mutations in $L R P 1 B$, which encodes a lipoprotein receptor-related protein. Two tumors contained missense mutations in $M E D 12$, a transcriptional co-activator that is recurrently mutated in uterine leiomyomas and breast fibroadenomas. ${ }^{23,24}$ One of the two MED12 mutations (p.L36R), found in a uterine adenomatoid tumor, localizes within an activating mutational hotspot that has been identified near the N-terminus of the protein. However, the possibility that this MED12 mutation represents contamination by an adjacent leiomyoma is a distinct possibility. No other genes sequenced in this cohort of 31 adenomatoid tumors contained recurrent genetic alterations (Supplementary Table 3). No chromosomal gains, losses or focal amplifications or deletions were identified in any of the 31 tumors (Supplementary Figure 1).

Sequencing of the four separate adenomatoid tumors in patient \#14 identified different somatic TRAF7 mutations in each tumor, confirming that these anatomically distinct tumors were also genetically distinct (Figure 6). No pathogenic alterations were identified in the germline of this immunosuppressed patient to account for the multiple adenomatoid tumors. In order to study potential intratumoral genetic heterogeneity, genomic DNA was isolated and sequenced from four different regions of the giant adenomatoid tumor in patient \#15. All four regions contained the identical TRAF7 and $L R P 1 B$ somatic mutations, and no private alterations were identified in any of the four regions, indicating that the TRAF7 and $L R P 1 B$ variants were likely early or initiating events in this tumor.

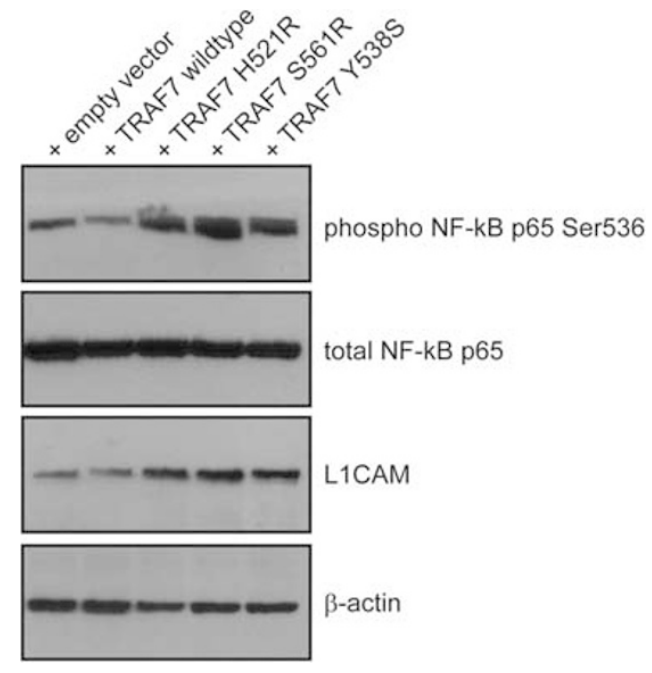

Figure 7 Western blots on total cell lysate from 293T cells after transfection with empty vector, wild-type TRAF7 or TRAF7 harboring three different mutations recurrently found in adenomatoid tumors.

\section{TRAF7 Mutations Drive Aberrant NF-kB Pathway Activation}

In order to study the functional effects of these recurrent TRAF7 mutations, we generated an expression vector for wild-type TRAF7, as well as three of the most common mutations observed in adenomatoid tumors (p.H521R, p.S561R and p.Y538S). As TRAF7 belongs to the family of TNF receptorassociated factors that are known to regulate nuclear factor-kappa B (NF-kB), ${ }^{25}$ we hypothesized that these recurrent TRAF7 mutations might cause adenomatoid tumors through deregulation of NF-kB signaling. Upon transfection of mutant but not wild-type TRAF7 into human embryonic 293T cells, we observed an increase in phosphorylation of the p65 subunit of NF-kB (Figure 7), a post-translational modification associated with activation of NF-kB signaling. ${ }^{26,27}$ L1 cell adhesion molecule (L1CAM) is a known transcriptional target of NF-kB and has emerged as a reliable surrogate marker for tumors with activated NF-kB signaling. ${ }^{28,29}$ We observed a robust increase in levels of L1CAM protein in cells expressing mutant but not wild-type TRAF7 (Figure 7). We therefore considered the possibility that TRAF7 mutations cause adenomatoid tumors of the genital tract by activation of NF-kB signaling.

To further assess this hypothesis, we performed immunohistochemistry for L1CAM protein on a series of adenomatoid tumors, as well as normal mesothelium and two other tumors of mesothelial origin-malignant peritoneal mesothelioma and multilocular peritoneal inclusion cyst, also known as benign multicystic mesothelioma. We observed strong membranous staining for L1CAM in all adenomatoid tumors $(n=8)$ (Figure 8, Supplementary Figure 2, Table 2). In contrast, no appreciable L1CAM staining was seen in normal 
$H \& E$

adenomatoid

tumor of uterus

thelium

on ovary

malignant

peritoneal mesothelioma
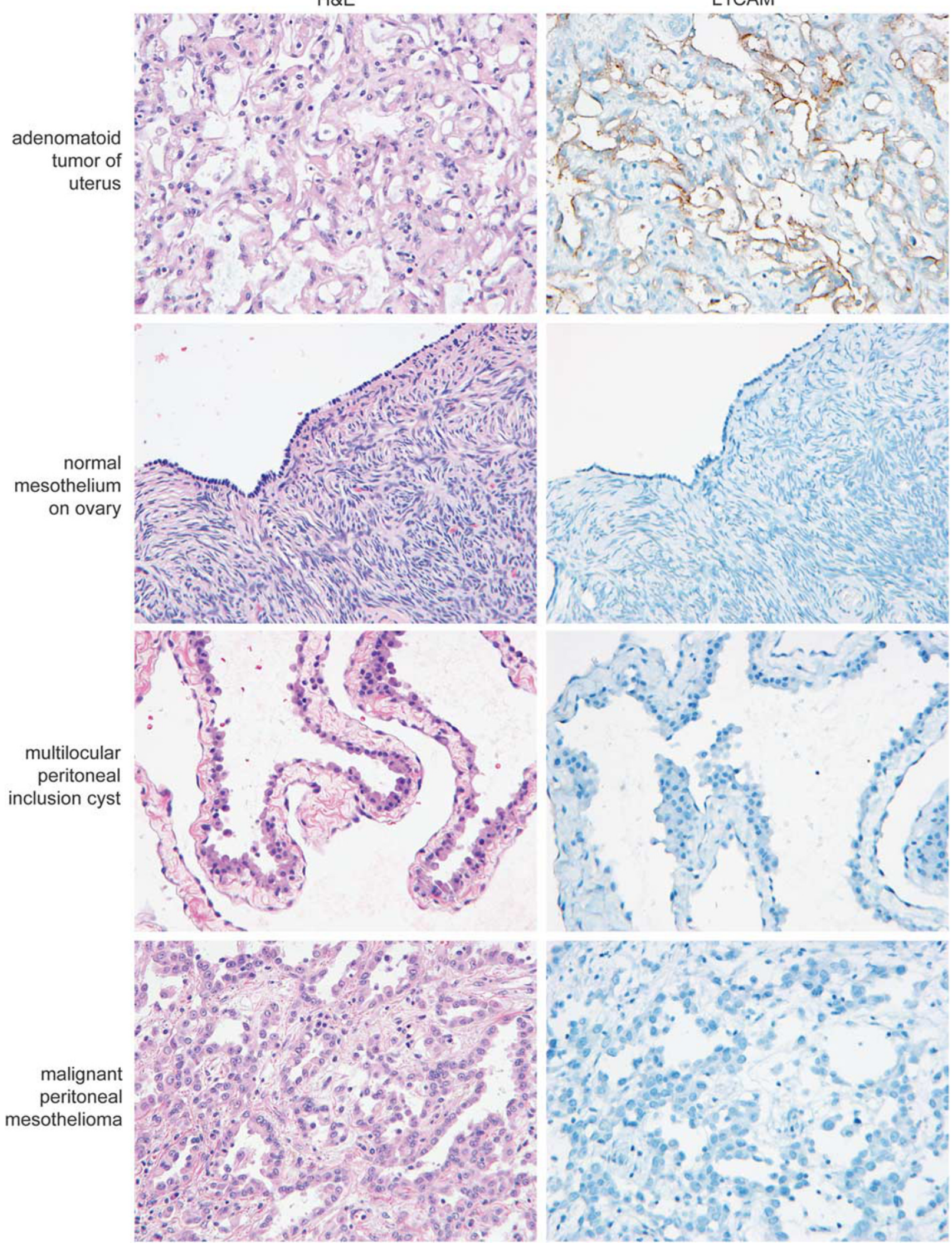

Figure 8 Immunohistochemistry for L1CAM demonstrates robust expression in adenomatoid tumors with the expected membranous staining pattern, whereas L1CAM expression is absent in normal mesothelial cells, malignant peritoneal mesotheliomas and multilocular peritoneal inclusion cysts. 
Table 2 L1CAM immunostaining results on normal mesothelium, adenomatoid tumors of the genital tract and other mesothelial lesions of the peritoneal cavity

\begin{tabular}{lccc}
\hline Tissue & Cases with L1CAM immunostaining & Total number of cases & \% Positive for L1CAM \\
\hline Normal mesothelium & 0 & 7 & $0 \%$ \\
Adenomatoid tumor & 8 & 8 & $100 \%$ \\
Malignant peritoneal mesothelioma & 0 & 7 & $0 \%$ \\
Multilocular peritoneal inclusion cyst & 0 & 6 & $0 \%$ \\
\hline
\end{tabular}

mesothelial cells lining organs of the peritoneal cavity $(n=7)$, nor was staining seen in malignant peritoneal mesotheliomas $(n=7)$ or multilocular peritoneal inclusion cysts $(n=6)$ (Figure 8 and Supplementary Figures 3 and 4). Together, these data suggest that TRAF7 mutations lead to the development of adenomatoid tumors, at least in part, through activation of NF-kB signaling.

\section{Discussion}

Our study identifies a defining genetic alteration in adenomatoid tumors of the genital tract, which was uniformly present in epididymal, uterine and fallopian tube tumors. Thus, in addition to morphologic and immunophenotypic similarities, adenomatoid tumors of the epididymis in males and fallopian tube and uterus in females also share a common genetic basis, and therefore are all likely to be a single tumor entity.

In addition to adenomatoid tumors of the genital tract, TRAF7 mutations have been recently identified at high frequency in intraneural perineuriomas, a rare nerve sheath tumor derived from perineurial cells. ${ }^{30}$ In addition, TRAF7 mutations have been identified in benign meningiomas, particularly those of the secretory variant and those located in the anterior skull base, where they frequently occur with concurrent mutations in KLF4, AKT1 or PIK3CA. ${ }^{31,32}$ Alterations involving $K L F 4, A K T 1$ or PIK3CA were not identified in any of the 31 adenomatoid tumors in this cohort, indicating that adenomatoid tumors are genetically distinct from meningiomas harboring TRAF7 mutations. Nevertheless, TRAF7 mutations appear to genetically define a group of neoplasms arising from cells whose function is lining or wrapping around vital organs such as the brain, peripheral nerves, testis, uterus and fallopian tube.

TRAF7 mutations have also been identified in a small subset (approximately 2\%) of malignant mesotheliomas of the pleural cavity. ${ }^{33}$ Whether these tumors instead represent misclassified adenomatoid tumors of the pleural cavity is a distinct possibility. Our recent genomic analysis of pathologically confirmed malignant mesotheliomas of the peritoneum did not identify any tumors harboring TRAF7 mutation. ${ }^{12}$ None of the adenomatoid tumors of the genital tract in the present cohort were found to harbor alterations in $B A P 1, N F 2$ or $C D K N 2 A$ that characterize the vast majority of malignant mesotheliomas. As such, mesothelial tumors of the pleural, peritoneal and other body cavities that are identified to harbor TRAF7 mutation should strongly raise the possibility of an adenomatoid tumor, especially if alterations typical of malignant mesothelioma or other diagnostic entity are not present.

The TRAF7 mutations identified in adenomatoid tumors in this study, as well as those found in meningiomas and intraneural perineuriomas, ${ }^{30-32}$ are all heterozygous missense mutations that cluster within a few mutational hotspots in the WD40 repeat domains at the C-terminus of the encoded TRAF7 protein. This genetic pattern of heterozygous missense mutations that cluster within a limited number of mutational hotspots is strongly suggestive that these are activating, gain-of-function mutations, as opposed to inactivating, loss-of-function events (which are typically truncating mutations scattered throughout a gene accompanied by loss of heterozygosity). Thus, TRAF7 is very likely to function as an oncogene, rather than a tumor-suppressor gene, in these tumor types.

The identification of TRAF7 mutations as the genetic basis for adenomatoid tumors provides a potential explanation for why immune dysregulation may contribute to the development of these tumors. TRAF7 encodes an E3 ubiquitin ligase that is a member of the family of TRAFs. This family of proteins has been implicated in regulation of a number of critical immunomodulatory signaling pathways involving NF-kB, interferon-regulatory factors, c-Jun N-terminal kinases and p38 mitogenactivated protein kinases. ${ }^{25,34}$ We hypothesize that immunosuppression causes an abnormal inflammatory state within mesothelial cells lining the peritoneal cavity that either causes selective pressure for the acquisition of activating TRAF7 mutation or potentiates the oncogenic effect of TRAF7 mutation once acquired, thereby promoting the formation of adenomatoid tumors. Although further studies are necessary to completely unravel the mechanisms by which TRAF7 mutations lead to the development of intraneural perineuriomas, meningiomas, adenomatoid tumors and perhaps other as-yet unidentified tumor types, our study provides the first evidence that activation of NF-kB signaling is likely to be at least one of the mechanisms by which TRAF7 mutations cause these specific tumor types. 


\section{Acknowledgments}

This study was supported by NIH Director's Early Independence Award (DP5 OD021403) and the UCSF Physician-Scientist Scholar Program to DAS. We thank the UCSF Brain Tumor Research Center (supported by NIH SPORE grant P50CA097257) for assistance with L1CAM immunohistochemistry.

\section{Disclosure/conflict of interest}

The authors declare no conflict of interest.

\section{References}

1 Nogales FF, Isaac MA, Hardisson D, et al. Adenomatoid tumors of the uterus: an analysis of 60 cases. Int J Gynecol Pathol 2002;1:34-40.

2 Sangoi AR, McKenney JK, Schwartz EJ, et al. Adenomatoid tumors of the female and male genital tracts: a clinicopathological and immunohistochemical study of 44 cases. Mod Pathol 2009;22:1228-1235.

3 Ferenczy A, Fenoglio J, Richart RM. Observations on benign mesothelioma of the genital tract (adenomatoid tumor). A comparative ultrastructural study. Cancer 1976;37:1478-1484.

4 Mackay B, Bennington JL, Skoglund RW. The adenomatoid tumor. Fine structural evidence for a mesothelial origin. Cancer 1971;27:109-115.

5 Taxy JB, Battifora H, Oyasu R. Adenomatoid tumors. A light microscopic, histochemical, and ultrastructural study. Cancer 1974;34:306-316.

6 Said JW, Nash G, Lee M. Immunoperoxidase localization of keratin proteins, carcinoembryonic antigen, and factor VIII in adenomatoid tumors. Evidence for a mesothelial derivation. Hum Pathol 1982;13: 1106-1108.

7 Livingston EG, Guis MS, Pearl ML, et al. Diffuse adenomatoid tumor of the uterus with a serosal papillary cystic component. Int J Gynecol Pathol 1992;11:288-292.

8 Cheng CL, Wee A. Diffuse uterine adenomatoid tumor in an immunosuppressed renal transplant recipient. Int J Gynecol Pathol 2003;22:198-201.

9 Bulent Tiras M, Noyan V, Suer O, et al. Adenomatoid tumor of the uterus in a patient with chronic renal failure. Eur J Obstet Gynecol Reprod Biol 2000;92: 205-207.

10 Acikalin MF, Tanir HM, Ozalp S, et al. Diffuse uterine adenomatoid tumor in a patient with chronic hepatitis $C$ virus infection. Int J Gynecol Cancer 2009;19: 242-244

11 Mizutani $\mathrm{T}$, Yamamuro $\mathrm{O}$, Kato $\mathrm{N}$, et al. Renal transplantation-related risk factors for the development of uterine adenomatoid tumors. Gynecol Oncol Rep 2016;17:96-98.

12 Joseph NM, Chen YY, Nasr A, et al. Genomic profiling of malignant peritoneal mesothelioma reveals recurrent alterations in epigenetic regulatory genes BAP1, SETD2, and DDX3X. Mod Pathol 2017;30:246-254.

13 Li H, Durbin R. Fast and accurate long-read alignment with Burrows-Wheeler transform. Bioinformatics 2010;26:589-595.
14 Li H, Handsaker B, Wysoker A, et al. The Sequence Alignment/Map format and SAMtools. Bioinformatics 2009;25:2078-2079.

15 Broad Institute. Picard. http://broadinstitute.github.io/ picard/.

16 Talevich E, Shain AH, Botton T, Bastian BC. CNVkit: genome-wide copy number detection and visualization from targeted DNA sequencing. PLoS Comput Biol 2016;12:e1004873.

17 Ye K, Schulz MH, Long Q, Apweiler R, Ning Z. Pindel: a pattern growth approach to detect break points of large deletions and medium sized insertions from paired-end short reads. Bioinformatics 2009;25: 2865-2871.

18 Wang K, Li M, Hakonarson H. ANNOVAR: functional annotation of genetic variants from high-throughput sequencing data. Nucleic Acids Res 2010;38:e164.

19 Garrison E, Marth G, Haplotype-based variant detection from short-read sequencing. arXiv $1207.3907 \mathrm{v} 2$ [q-bio. GN].

20 Rausch T, Zichner T, Schlattl A, et al. DELLY: structural variant discovery by integrated paired-end and split-read analysis. Bioinformatics 2012;28: i333-i339.

21 Dalgliesh GL, Furge K, Greenman C, et al. Systematic sequencing of renal carcinoma reveals inactivation of histone modifying genes. Nature 2010;463:360-363.

22 Fontebasso AM, Schwartzentruber J, Khuong-Quang DA, et al. Mutations in SETD2 and genes affecting histone H3K36 methylation target hemispheric highgrade gliomas. Acta Neuropathol 2013;125:659-669.

23 Makinen N, Mehine M, Tolvanen J, et al. MED12, the mediator complex subunit 12 gene, is mutated at high frequency in uterine leiomyomas. Science 2011;334: 252-255.

24 Lim WK, Ong CK, Tan J, et al. Exome sequencing identifies highly recurrent MED12 somatic mutations in breast fibroadenoma. Nat Genet 2014;46:877-880.

25 Xie P. TRAF molecules in cell signaling and in human diseases. J Mol Signal 2013;8:7.

26 Lawrence T, Bebien M, Liu GY, et al. Ikkalpha limits macrophage NF-kappaB activation and contributes to the resolution of inflammation. Nature 2005;434: 1138-1143.

27 Mattioli I, Sebald A, Bucher C, et al. Transient and selective Nf-Kappa B p65 serine 536 phosphorylation induced by $\mathrm{T}$ cell costimulation is mediated by I Kappa B Kinase Beta and controls the kinetics of p65 nuclear import. J Immunol 2004;172:6336-6344.

28 Parker M, Mohankumar KM, Punchihewa C, et al. C11orf95-RELA fusions drive oncogenic NF-kB signaling in ependymoma. Nature 2014;506:451-455.

29 Figarella-Branger D, Lechapt-Zalcman E, Tabouret E, et al. Supratentorial clear cell ependymomas with branching capillaries demonstrate characteristic clinicopathological features and pathological activation of nuclear factor-kappaB signaling. Neuro Oncol 2016;18: 919-927.

30 Klein CJ, Wu Y, Jentoft ME, et al. Genomic analysis reveals frequent TRAF7 mutations in intraneural perineuriomas. Ann Neurol 2017;81:316-321.

31 Clark VE, Erson-Omay EZ, Serin A, et al. Genomic analysis of non-NF2 meningiomas reveals mutations in TRAF7, KLF4, AKT1, and SMO. Science 2013;339: 1077-1080.

32 Reuss DE, Piro RM, Jones DT, et al. Secretory meningiomas are defined by combined KLF4 K409Q 
and TRAF7 mutations. Acta Neuropathol 2013;125: 351-358.

33 Bueno R, Stawiski EW, Goldstein LD, et al. Comprehensive genomic analysis of malignant pleural mesothelioma identifies recurrent mutations, gene fusions and splicing alterations. Nat Genet 2016;48: 407-416.

34 Zotti T, Scudiero I, Vito P, Stilo R. The emerging role of TRAF7 in tumor development. J Cell Physiol 2017;232: 1233-1238.

Supplementary Information accompanies the paper on Modern Pathology website (http://www.nature.com/ modpathol) 